\title{
Türkiye'deki Gazetecilerin Instagram Hesaplarının İçerik Analizi Yöntemiyle İncelenmesi
}

DOI: $10.26466 /$ opus. 830479

\author{
Aylin Tutgun-Ünal $^{*}$ - Ayşe Sena Kurt** \\ * Dr. Öğretim Üyesi, Üsküdar Üniversitesi, İletişim Fakültesi, İstanbul/ Türkiye \\ E-Posta: aylin.tutgununal@uskudar.edu.tr \\ ORCID: 0000-0003-2430-6322 \\ ** Doktora Öğrencisi-Klinik Psikolog, Üsküdar Üniversitesi, İstanbul/Türkiye \\ E-Posta: klinikpsikolog.aysesenakurt@gmail.com ORCID: 0000-0001-5644-7571
}

\begin{abstract}
Öz
Haber üretim ve tüketimine olanak sağlayan sosyal medya mecraları gazeteciliği şekillendirmiş, Instagram gazeteciliği de görsel haberciliğin popüler hale gelmesinde bir çı̆̆ı açmıştır. Şimdilerde kişilerle ilgili herhangi bir konuda merak duygusunun giderilmesi amactyla ilk tercih edilen platform haline gelen Instagram, gazetecilere hem kişisel hem de alanlarıla ilgili paylaşım yapmalarına sağladığı imkân ile bir nevi kanaat önderlerine destekleyici rol üstlenmiştir. Bu araştırmada Türkiye'deki Instagram takipçisi açısından en yüksek sayıya sahip ilk beş arasında yer alan üç gazetecinin hesaplarının içerik analizi yöntemiyle incelenmesi amaçlanmıştır. Bu amaç doğrultusunda İsmail Küçükkaya, Pelin Kaya, Ayşe Arman'ın Instagram hesabı 2020 yılında Haziran ayında "Gazetecinin Instagram Kimlï̆i", "İçerik" ve "Etkileşim" başlıkları altında sinıflandırılarak incelenmiştir. Araştırmada elde edilen bazı bulgular şu şekildedir: (a) Hashtag kullanımı takipçi sayısı artışını etkilemektedir, (b) İsmail Küçükkaya iş alanından ziyade hesabından \%80 kişisel paylaşımlar yapmaktadır, (c) Bir ay boyunca 80 gönderi ile en çok Ayşe Arman paylaşım yapmıştır, ikinci sırada 56 gönderi ile İsmail Küçükkaya, üçüncü sırada 25 gönderi ile Pelin Kaya gelmektedir, (d) En çok kişisel paylaşımlar beğenilmektedir. Araştırma sonucunda gazetecilerin topluma yön verme fonksiyonunun olduğu ve bu doğrultuda geniş kitleler tarafindan kişisel paylaşımlar dahil olmak üzere dikkatle takip edildiği bir kere daha gündeme gelmiştir. Bu bağlamda ülkemizde en çok takip edilen gazetecilerin paylaşım verilerinin Instagram gazeteciliği hakkında ipucu sağlayabileceği düşünülmektedir.
\end{abstract}

Anahtar Kelimeler: Instagram Haberciliği, Sosyal Medya Gazeteciliği, Gazeteciler 


\title{
Examining Journalists' Instagram Accounts in Turkey: A Content Analysis
}

\begin{abstract}
Social media channels that enable news production and consumption have shaped journalism, and Instagram journalism has made a breakthrough in the popularization of visual journalism. Nowadays, Instagram, which has become the first preferred platform to eliminate the feeling of curiosity about any subject, has assumed a supportive role for opinion leaders with the opportunity it provides to journalists to share both personally and in their fields. In this research, the aim of the study was to examine with the content analysis method the accounts of three journalists who were among the top five journalists with the highest number of Instagram followers in Turkey. For this purpose, the Instagram account of İsmail Küçükkaya, Pelin Kaya, Ayşe Arman was classified and investigated in June 2020 under the titles of 'Journalist's Instagram Identity', 'Content' and 'Interaction'. The main results are summarized as follows: (a) The use of hashtags affects the increase in the number of followers, (b) İsmail Küçükkaya makes $80 \%$ personal shares from his account rather than his business area, (c) Ayşe Arman who shared the most posts on Instagram compared with the other two journalists shared 80 posts in a month. The second one is İsmail Küçükkaya with 56 posts and Pelin Kaya with 25 posts in the third place. d) Personal posts are the most liked. As a result of the research, it was once again brought to the agenda that journalists have the function of guiding the society and in this direction, they are carefully followed by large masses, including personal posts. In this context, it is thought that the sharing data of the most followed journalists in our country can provide clues about Instagram journalism.
\end{abstract}

Keywords: Instagram Journalism, Social Media Journalism, Journalists 


\section{Giriş}

Web 2.0 teknolojileri ile ortaya çıkan sosyal medya ağları özellikle mobil telefonlara kurulan uygulamalar ile erişim sağlanarak her yaştan bireyin katıl1mıyla yoğun kullanılmaktadır. Günümüzde sosyal medyada vatandaşların söyledikleri birinci ağızdan enformasyon değeri taşımaktadır. Artık merak edilen bir konuda bilgi araştırmak için öncelikle sosyal medya hesapları kontrol edilir hale gelmiştir.

Sosyal medyanın haber ajansı görevi gördüğü günümüzde pek çok örnekte olay yeri fotoğrafı ve videolar ile birinci kaynak olarak haber kuruluşlarına hizmet ettiği ve gazetecilerin neredeyse tamamına yakınının sosyal medya mecralarından yararlandığı görülmektedir. Bu noktada vatandaşların çektikleri fotoğraf ve videoları paylaşarak birinci ağızdan enformasyon yayması ile haberciliğe dahil olmaları giderek yaygınlaşan bir durumdur. Böylece sosyal medya platformları, habercilik yapmak isteyen vatandaşların bağımsız olarak video kurgulama ve metin yazarlığı beceriyle kendilerini geliştirme ortamları olarak da fonksiyonel olmaktadır.

Araştırmalarda önceleri gazete, radyo, televizyon gibi kitle iletişim araçları ile insanların ilişkisi incelenirken (Pecchioni, Wright ve Nussbaum, 2005; Williams, 2001; Williams ve Harwood, 2008), şimdilerde WEB 2.0 teknolojilerinin hızla yaygın hale gelmesiyle farklı kuşakların bilgisayar, internet, cep telefonu ve özellikle de sosyal medya ile ilişkisi incelenmektedir (Asmafiliz ve Şalvarcı Türeli, 2018; Dyke, Haynes ve Ferguson, 2007; Kuyucu, 2017; Özdemir, 2017; Sağır ve Eraslan, 2019; Süer, Sezgin ve Oral, 2017; Tutgun-Ünal ve Deniz, 2020).

Sosyal medya adında anlaşılacağı gibi çeşitli kültürlerdeki insanların bir arada bulunduğu katılımcı bir platformdur. Bu ortamda her yaştan birey kendi ilgi alanları doğrultusunda enformasyon yaymaktadır. Hatta birer gazeteci kimliğine bürünerek sosyal medya sayfalarından, özellikle anlık ve kolay paylaşımda bulunabileceği hikâye bölümünden içerik paylaşarak ağdaki diğer kullanıcıları haberdar etme çabasındadır. Bu durum yeni bir gazetecilik anlayışının da ortaya çıkmasına sebep olmuştur. Aynı zamanda araştırmac1lar geleneksel gazeteciliğin yeni medya sayesinde katilımcı gazetecilik ile değiştiğini bildirmektedir (Lasica 2003; Singer ve diğ. 2011, s. 2). 
Sosyal medya uygulamalarını her kuşak kendi ilgisi ve amacı doğrultusunda seçmektedir ve kullanmaktadır. Yapılan sosyal medya kuşakları araştırmasında hangi platformlarda hangi kuşakların daha fazla kümelendiği belirlenmiştir (Tutgun-Ünal ve Deniz, 2020). Buna göre genç kuşakların görsel özelliklerin ön planda olduğu Instagram ve YouTube uygulamalarını yoğun kullandığı belirtilmektedir. Bu doğrultuda haber niteliğindeki içeriklerin de farklı şekillerde sunulduğu görülmektedir. Instagram için özel filtre/makyaj programları ile basitleştirilmiş video kurgu programları ortaya çımıştır ve içeriklerini bu programlarda düzenleyen gençler kendi beğenileri doğrultusunda düzenleyerek paylaşmaktadır.

Sosyal medya gazeteciliği anlayışına göre, görsel paylaşıma önem veren genç kuşaklara haber sunulurken fotoğraf/video, kısa metinler ile bakıp geçebilecekleri biçimde haberin kurgulanması, özelliklerine ve bakış açılarına uygunluğu da sağlandığında etkili olabilmektedir. Özellikle söz konusu hususların hikâye haberciliği ile sağlanabileceği göz önünde bulundurulması gerekir ki, hikâye özelliğinin pek çok uygulamada aynı anda paylaşılabilecek şekilde imkân sağladığı görülmektedir. Kısa zamanda hızlı bir şekilde bakıp geçmeye imkânı sağlayan özellik olarak hikâye özelliği pek çok sosyal medya uygulamasına yerleştirilmiştir ve genç kuşaklara hitap etmektedir. Belirli süre sınırlaması sayesinde hikâye uzun olsa bile kısa parçalara bölünmesi gerektiğinden genç kuşağın içeriğe bakıp geçmesini olanaklı kılmaktadır (Tutgun-Ünal, 2020a).

Sosyal medyada hashtag (\#) mekanizması yayılan enformasyonların bir araya getirilerek farklı görüşlerin görüntülenmesine olanak sağlanmaktadır. Belirli bir haberin çeşitli bölgelerdeki kullanıcılar tarafından paylaşılması mümkündür ve haber denetimi sosyal medyanın kendi mekanizmasında gerçekleşmektedir. Sosyal medyanın kendi iç denetim mekanizmasında denetçiler bir nevi çevrimiçi kullanıcılar olup görüş paylaşımında, beğeni alışverişinde veya tekrar paylaşımda (retweet, repost, repin vb.) bulunabilmektedir. Böylece haberin farklı açılardan yorumlanması ile etkileşim ve devamlılık sağlanmaktadır. Böylece çevrimiçi ağlarda genişleyerek yayılım gösteren yeni bir gazetecilik anlayışı ortaya çıkmaktadır.

Yeni habercilik anlayışına göre, haberciliğe yönelik içeriğin tüketimi, dağıtımı ve üretiminin temelde değişikliğe uğramıştır. Bir zamanlar haber üreticileri aynı zamanda distribütörleri (dağıtımcıları) olma eğilimindeyken şimdilerde tüketicilerin dijital platformlarda distribütör rolünü de üstlendiği 
vurgulanmaktadır (İrvan, 2014; Tutgun-Ünal, 2020b; Wilding ve diğ., 2018). Sosyal medya gazeteciliğinde haberin üreticileri, tüketicileri ve dağıtımcıları da çevrimiçi kullanıcılar olup yatay iletişim modelinde olduğu gibi eşitlenmiş seviyededir.

Böylece yorum ve haber ayrımının giderek bulanıklaştığı birbiri içinde zaman zaman geçişkenlik gösterdiği ve haber tanımlamalarının daha geniş ele alındığı belirtilmektedir (Lamble, 2011; Marwick 2018, p. 504; Wilding ve diğ., 2018). Bu bağlamda, sosyal medya gazeteciliği ile haber tanımlarının yenilendiği söylenebilir. Haberin, geniş çaptaki umursanan konulardaki enformasyonel içerikler olarak tanımlandığına rastlanmaktadır (Harcup ve O'Neill 2017, s. 1482).

Sosyal medyanın yaygınlığıyla birlikte, habercilik yerine haber içeriklerinin önemsendiği görülmektedir. Çünkü herhangi bir toplumsal olay veya doğal bir afet olduğunda ilk haber kontrolünün yapıldığ yer sosyal medya platformları olduğu görülmektedir. Wilding ve diğerleri (2018) gazeteciliği, enformasyon toplayarak ve hikâye anlatımı tekniklerini kullanarak haber üretme pratiği olarak tanımlamaktadır. Sosyal medya ağlarında tüm kuşaklar gazetecilik ilkelerine uygun kurgulanmış haber içerikleri paylaşma çabası içindedir. Çevrelerinde gördükleri herhangi bir olayı fotoğraflayıp diğer metin, video, animasyon gibi multimedya içerikleri ile destekleyerek paylaşmayı yaşam tarzı haline getirmiştir. Üstelik söz konusu paylaşımları yapabilmek için gazetecilik mesleğinden olmak gerekmemektedir.

Yeni medya ile özellikle gazetecilerin değil gazetecilik içeriğinin kabul gördüğünün vurgulanması sosyal medyada üretilen haber maksatlı içeriklerin sosyal medya gazeteciliğine hizmet ettiğini ortaya koymaktadır. Sosyal medya gazeteciliği kavramının ortaya çıkmasında tüm kuşakların payı büyüktür. Böylece her yaş grubundan kullanıcının maksatlı veya maksatsız (öylesine) yaydığı enformasyonun haberciliğe hizmet ettiği ve çevrimiçi ağlardaki mikro düzeyde bireyleri makro düzeyde toplumu ve tüm dünyayı etkilediği bir gerçektir.

Pew Araştırma Merkezinin bir çalışması, Amerikalı yetişkinlerinin üçte ikisinin (yüzde altmış sekiz) sosyal medyadan haber aldığını ve daha çok Facebook'un haber almak için tercih edildiğini (yüzde kırk üç) göstermiş olup ikinci sırada YouTube (yüzde yirmi bir), üçüncü sırada Twitter (yüzde on iki) gelmiştir. Avustralya'da da ilk sırada Facebook haber almada ön plana çıkmaktadır (Park ve diğ., 2018). 
Araştırmalar zaman geçtikçe farklı uygulamaların popüler olduğunu göstermiştir. Türkiye'de yapılan bir araştırmada, Tutgun-Ünal ve Deniz'e (2020) göre orta yaş ve üzeri (1980'den önce doğanlar) Facebook kullanırken genç kuşaklar (1980 ve sonrası doğanlar) birinci sırada Instagram'ı kullanmaktadır. 2000 yılı ve sonrası doğanların ise Instagram ve YouTube kullanım oranları birbirine yakın bulunmuştur.

Diğer yandan, Z kuşağının teknolojiyle doğduğu ve büyüdüğü belirtilmektedir. Z kuşağının yaşça büyük bir kısmı lise öğrencilerinden oluşurken bir kısmı da henüz ilköğretime başlamamış çocukları kapsamaktadır. YouTube kanallarından çocuklara yönelik pek çok video içeriğinin yayımlandığ ve çocukların rastgele tıklayarak bu içeriklere ulaştığı düşünüldügünde çocuklara yönelik habercilik anlayışının da farklı boyutta olduğu ve ayrıca ele alınması gerekliliği ortaya çıkmaktadır. Bu araştırmada Instagram haberciliğ $i$ kapsamında ülkemizdeki takipçi sayısı en yüksek gazetecilerin Instagram hesapları incelenerek gazetecilerin kanaat önderi olmadaki fonksiyonelliğinde paylaşım özelliklerinin ve etkileşimlerin etkisi olup olmadığının incelenmesi amaçlanmıştır.

\section{Instagram Haberciliği}

Günümüz teknoloji çağında sosyal medya veya sosyal ağ siteleri başta Facebook, Instagram, Snapchat, Twitter uygulamaları olmak üzere, hayatımızın vazgeçilmez bir parçası haline gelmiştir. Son on yılda tahmin edilenden çok daha fazla sayıda sosyal medya uygulaması, milyonlarca kullanıcısına sınırsız zaman diliminde erişim sağlaması sebebi ile önemli bir popülerlik kazanmıştır. Bunların başında da Instagram uygulaması göze çarpmaktadır. Sosyal medya kullanımındaki hızlı artışla birlikte, çoğu işletme ve kuruluş, teknolojiyi başarılı bir pazarlama aracı, haber ve bilgi iletmek için bir kanal olarak kullanmaya başlamıştır. Instagram da bunlardan biridir. Instagram, kullanıclarının gönderilerini, hikayelerini, fotoğraf ve video paylaşımların $1 \% 70$ oranında takipçisine eriştirme olanağını sunmaktadır (Golbeck, 2015). Uygulama ilk olarak 2010 yılında tanıtılmıştır ve daha sonra Facebook tarafından satın alınmıştır. Bu uygulamayı popüler seviyede tutan etkenin, elbette kullanıcı kitlesinin taleplerini ve değişen sistemi göz önünde bulundurması, kendini güncellemeye ve yeniliklere açık bir şekilde çalışmalarını sürdürüyor olması gösterilmektedir. 
Instagram hikâye anlatımı, filtreleme/düzenleme ile fotoğraf, video paylaşımı, geçmiş paylaşımların bir arada toplandığı film rulosu gibi çeşitli görsel özellikler sunarak gazetecilik alanı için cazip hale gelmiştir. Dünyaca bilinen çeşitli gazete ve dergilerin takipçi sayıları incelendiğinde, The NewYork Times'ın 10 milyon, The Washington Post'un 3,5 milyon Instagram takipçisi olduğu görülmektedir. Moda ve stil dergisi olan Vogue Paris' in ise 6,8 milyon Instagram takipçisi olduğu dikkat çekmektedir. Buna göre çeşitli ilgi alanlarındaki kullanıcılardan gündemle ilgili haber alma ihtiyacında olanlara kadar azımsanmayacak kullanıcı kitlesinin Instagram kullanırken bir yandan haber içeriklerine ilgi duydukları söylenebilir.

Ülkemizde basın yayın sektöründe haber ajanslarının sosyal medya hesapları incelendiğinde, 1 milyonun üzerinde Instagram takipçisi ile Anadolu Ajansının yer aldığı, haftalık takipçi artışının 3 binlerde, aylık takipçi artışının ise 15 binlerde olduğu görülmektedir. Böylece basın yayın sektörüne hizmet sunan medya kuruluşlarının artık Instagram kitlelerine hitap etmek için görsel ve hikâyeleştirilmiş içerikler sunarak bu mecrada varlıklarını sürdükleri bir dönemden geçtiği ortadadır.

Gazetecilerin sosyal medyayı tüketicilerle bir etkileşim aracı ve hikâye anlatma platformu olarak kullanmayı öğrenmeleri her zamankinden daha önemli görülmektedir. Buna göre Willnat ve Weaver'ın (2014) araştırmasinda, profesyonel gazetecilerin sosyal medya, fotoğrafçlık ve multimedya hikâye anlatımında daha fazla eğitime ihtiyaç duydukları üç alan olarak tanımladıkları bulunmuştur. Byrd ve Denney (2018) bu üç becerinin Instagram'da hikâye anlatıcıllğının gerekliliği olduğunu ileri sürerek üniversite öğrencilerinin haber yazma dersinde Instagram'da hikâye anlatımının faydalarını, sonuçlarını keşfederek müfredata dahil edilip edilemeyeceğini araştırmayı hedeflemiştir.

Araştırmaya göre, Amerika'daki bir Üniversite'de, öğrencilerden Instagram'ı bir haber aracı olarak kullanıp, eğitim gördükleri üniversite kampüslerinin bulunduğu şehirlerdeki halkın polis ve hukuk algısına yönelik araştırma yapmaları istenmiştir. Eğitmenler tarafından, "Siyahilerin Yaşamları da Değerlidir!" hareketine bir yanıt olarak, polis sorunu ve hukuk yaptırımlarına yönelik halkın nabzını ölçmek için öğrencilerin sadece zor sorular sorması değil aynı zamanda bu soruları çeşitli gruplara yöneltmeleri de beklenmiştir. Buradaki çeşitlilik; ırk, yaş, yetenek, sosyoekonomik durum ve cinsiyeti simgelemektedir. Her öğrenci bunun için Instagram hikayelerinden 12 
fotoğraf ve röportaj yayınlamak zorundadır. Her görüşme için benzer sorular üzerinde durulmuştur: "Polisin tutumu hakkında nasıl hissediyorsun?" gibi. Verilen cevaplarla uygun olacak şekilde hashtagler (\#) kullanılarak paylaşımlar yapılmıştır. Ardından eğitmenler, Qualtrics programı aracılı̆̆ı ile öğrencilerin deneyimlerine yönelik 11 soruyu, o dersin Facebook sayfası üzerinden paylaşarak ankete katılmalarını talep etmiştir. Yapılan anket gönüllülük esasına dayandırılmıştır ve soruların anonim bir profil üzerinden cevaplandırılması talep edilmiştir. Ankette hem nicel hem de nitel sorular yer almakta olup sorular genel itibari ile açık uçlu seçilmiştir. Sonuç olarak, 30 öğrenciden 27'si bu ankete katılmıştır.

Öğrencilerin geneli kadın olmakla birlikte, \%74.07'si üst düzey öğrenciler, \%77,78'i son sınıf öğrenciler, \%14,81'i ergenler, \%7.41'i ikinci sınıf öğrencilerden oluşmaktadır. Katılımcıların \%85,19'u gazetecilik, \%11.11'i halkla ilişkiler ve \%3,70'i kitle iletişim bölümünden olmayan öğrencilerinden oluşmaktadır. Katılımcıların çoğunluğu gazetecilik ve multimedya (\%33,33), yayınc1lik $(\% 18,52)$, spor $(\% 11,11)$ ve radyo $(\% 7,41)$ alanlarında kariyer yapmayı planlamakta olup, halkla ilişkiler $(\% 14,81)$ ve sinema $(\% 14,81)$ alanında kariyer yapmaya başlamış öğrenciler de bulunmaktadır. Öğrenciler Instagram'ın Hikâye özelliğini kullanmanın onlara kattı̆̆ en önemli iki şeyden bahsederken genel anket profili, hassas konular hakkında sorular yöneltirken nasıl ofansif bir tutum sergilemeden bunu başarabileceğini öğrendiğini ve ikinci olarak herkesin kendi düşünce ve duygularını -sizinle aynı görüşü paylaşmasa dahi- duyurmayı hak ettiği cevabını vermiştir. Ardından en sık verilen cevapların Instagram Hikâyelerinde oluşturdukları temaların zorluğu hakkında olduğu görülmüştür.

Araştırmada, 12 fotoğraf paylaşımının prezantabl olabilmesi için düşünüldügünden çok daha uzun bir hazırlık süreci gerektirdiği, fotoğraf paylaşım planlamasının harekete geçilmeden uzun bir süre önce organize edilmesinin icap ettiği ve insanlarla röportaj yapmaya başlamadan önce her şeyin tümüyle organize edilmiş olmasının şart olduğu üzerine cevaplar verilmiştir. Birkaç öğrenci ise röportaj tekliflerinin çeşitli sebepler ile reddedilmesi üzerine değinmiştir. Bir öğrenci, "İnsanlara polis şiddeti hakkında tartışma yaratacak bir soru sorduğunuzda donup kalıyorlar." cevabını verirken diğeri, "Bir kişiden iyi bir röportaj çıkarabilmek için en az beş soru gerekiyor." demiştir. Birçok öğrenci ayrıca fotoğraf becerilerini geliştirmenin önemi üzerinde durmuştur. Instagram'da kaliteli bir hikâye yaratmak için harcadıkları 
eforun, fotoğraf çekme becerilerini geliştirdiğine değinmişlerdir. Genel itibari ile Instagram'ın Hikaye özelliğini kullanmanın onları hangi yönde geliştirdiğine yönelik sorulara birden fazla cevap verildiği görülmektedir: fotoğraf yeteneğimi geliştirmemi sağladı diyenler \%53.85 iken röportaj yapma yeteneğimi geliştirdi diyenler $\% 50$, nasıl adım atılması gerektiğine yönelik yeteneklerimi geliştirdi diyenler $\% 42.31$, yazma yeteneğimi geliştirdi diyen $\% 19.23$, düzenleme yeteneğimi geliştirdi diyen \%15,38 ve diğer yazı başlığı altındaki şıklar için yeteneklerini geliştirdiklerine yönelik cevaplar \%3.85'tir (Byrd ve Denny, 2018).

Yürütülen bu çalışma sonuçları göz önünde bulundurulduğunda ve çalışma bütünüyle değerlendirildiğinde, Instagram haberciliğinin profesyonel bir haberciliğin gerekliliğinde olduğu gibi yüz yüze iletişimi, haber kaynağ1nın reklamına yönelik özenli bir çalışmayı ve araştırma sorularının detaylı ve intizamlı bir şekilde hazırlanması gerektiği göz önünde bulundurulduğunda ve yapılan başka çalışmalar ile kıyasladığında (örn, Kinsky ve Bruce, 2016) günümüzün popüler twitter haberciliğinden çok daha detaylı ve özenli bir çalışma yürütülmesi gerektiği görüşünü yansıtmaktadır.

Günümüz haber kaynaklarına bakıldığı zaman, tüketicinin tercihleri ve alışkanlıkları göz önünde bulundurulduğunda, gerçek şudur ki, haber değeri taşıyan bir olayın ses duyurması için seçtiği kaynaklar, tüketicinin yoğunlaştığı sosyal medya uygulamalarının etkisi altındadır (Jenkins, 2006, p. 3). Instagram gazeteciliğinin başarısının birçok faktörden kaynaklandığı bilinmektedir. Ancak bunlardan en önemlisi olarak arz talep ilişkisinin sonuna kadar karşılıklı etkileşimini sürdürüyor olması gösterilebilmektedir. Eski sistem habercilik hayattaki süreğen değişimlerin yansıtılmasında yavaş kalmakla birlikte, takipçilere söz hakkı tanıyamaması bakımından teknolojik çağa ayak uyduramamaktadır.

Günümüz yeni kuşağının özellikle, habere anında ulaşma talebi ve kendi sesini ve düşünceleri yansıtma arzusu sebebi ile üzerine çalışılıp gün içerisinde sunulan eski habercilik geleneği yeni neslin tercihi olmaktan çıkmıştır. Her şeyden önce, CNBC'nin Z kuşağı çocukları arasında yaptığı bir anket göz önünde bulundurulduğunda, öğrenciler bir zamanlar $Y$ kuşağ için oldukça popüler olan Facebook'u dahi neredeyse hiç kullanmadıklarını belirtmişlerdir. Facebook'tan daha "havalı" olduğunu keşfettikleri için her gün Instagram ve Snapchat kullandıklarını dile getirmişlerdir. (Handley, 2019). Bu ne- 
denle, teknolojik değişikliklere uyum sağlayan ve yeni neslin tercihlerini karşlamak için esnek bir tutum sergileyebilen habercilerin ve haber kaynaklar1nın sosyal medya gündeminde daha çok konuşulması ve ön sıralamalara çıkması beklenen bir sonuçtur.

Bir gazeteci olan Justin Sablich (2019), Instagram'in aylık 800 milyondan fazla kullanıcısı olduğunu ve yapılan bir araştırmaya göre ise Instagram'da markalarla etkileşimin Facebook'tan 10 kat, Pinterest'ten 54 kat ve Twitter'dan 84 kat fazla olduğunu kaleme almıştır. Buna göre, gazeteciler, kişisel markalarını oluşturmak ve yaptıkları harika işi duyurmak için bunu doğru şekilde kullandıklarında hedef kitleye ulaşmalarının daha kolay olacağını iddia etmektedir. Ayrıca, yeterince "popüler" olunur ise, Instagram okuyucularının doğrudan çevrimiçi içeriklerine gönderimlerin aktarılmasına izin verebileceğini de vurgulamaktadır. Instagram'da başarılı bir profil oluşturmak için elbette püf noktaları iyi öğrenmek ve uygulamaya kısa sürede geçmek gerekliliğinden bahseden Sablich, Instagram gazeteciliğinde popülerleşebilmek için şu konularda ustalaşılması gerektiğini vurgulamıştır: Filtreleme, hashtag, aktif hikâye paylaşımı ve benzeri diğer içerikler (Sablich, 2019). Elbette bunları aktif olarak kullanırken bir gazeteci olarak arka planı paylaşmak, genç neslin ilgi alanlarına yönelik ilgi çekici görseller, hobi alanları, müzik ve sanat ile iç içe olmak da diğer gazeteciler ile rekabette bazı üstünlükler kazandırabilmektedir.

Bu doğrultuda, bu araştırmanda Türkiye'deki gazetecilerin Instagram hesaplarının içerik yöntemiyle incelenmesi amaçlanmıştır.

\section{Yöntem}

Araştırmanın evrenini Türkiye'deki Instagram gazetecileri oluşturmaktadır. Araştırmanın örneklemi oluşturulurken öncelikle Instagram takipçi sayıları açısından gazeteciler sıralanmış olup, takipçi sayısı 1.000.000 kişinin üstünde olan ve tek kişi tarafından yönetilen 5 gazetecinin hesapları dikkate alınmıştır. Daha sonra içlerinden farklı ilgi alanlarından olmaları ölçüt kabul edilerek, 3 tanınmış ismin Instagram hesapları örneklemi oluşturmuştur.

Örneklemi oluşturan hesaplar İsmail Küçükkaya, Pelin Kaya, Ayşe Arman'dır. Gazetecilerin ilgi alanları incelendiğinde, Pelin Kaya'nın moda ve sosyete, Ayşe Arman'ın röportaj haberleri, İsmail Küçükkaya'nın ise haber 
sunuculuğu yapmasından dolayı gündem haberciliği ile ilgilendiği görülmektedir.

Araştırmada yöntem olarak, içerik analizinden yararlanılmıştır. İçerik analizi, sosyal bilimlerde iletişim şeklinin sistematik, niceliksel ve nesnel olarak ele alınması olarak ifade edilmekte olup, nesnellik, çalışma kapsamında belirlenen analiz sınıflandırmalarının farklı kişilerce aynı içeriğin incelenmesi süreci sonunda eş sonuçların elde edilmesiyle ilişkilidir (Keskin ve Çilingir, 2010, s. 59). Sistemlilik ise, nesnelliğe çeşitli benzerlikler gösteren, belirli kriterlerin aynı türde içerik çözümlenmesi yapılacak metnin bütünü üzerinde gerçekleştirilmesidir.

İçerik analizi temel sınıflandırma sistemine dayanmaktadır. İçerik analizinin amacı, sınıflandırma sisteminin dayandığı kategorilerin varlığını ortaya koymasının haricinde bunların ne anlama geldiği ve genel görünüm için hangi ağırlığa sahip olduğunu belirtmektedir (Yeniçıktı, 2016, s. 103). Ana ölçüt olarak son 1 aydaki beğeni ve yorum sayıları dikkate alınmıştır. Araştırmada, Instagram verileri oluşturulurken son 1 aydaki (1 Haziran-30 Haziran) paylaşımlar kullanılmıştır. Çalışmada 3 farklı alanda olan 3 tanınmış ismin aldıkları beğeni, yorum sayıları karşılaştırılmış, paylaşım içerikleri değerlendirilmiştir. Ayrıca 3 hesaba ilişkin betimleyici istatistikler de verilmiştir. Son 1 ayda Ayşe Arman'ın hesabında 80, İsmail Küçükkaya hesabında 56, Pelin Kaya'nın hesabında 25 paylaşım yapılmıştır. Videolardan görüntülenme sayısı beğeni yerine kullanılmıştır. Paylaşımların içerikleri 3 başlıkta kategorize hale getirilmiştir.

Gazetecinin Instagram Kimliği: Gazetecinin adı, Instagram profil adı ve Instagram profilinin açıklama kısmında kendisine yönelik açıklama ve bilgilerinin mevcudiyeti olarak belirlenmiştir.

İçerik: Gazetecinin takipçi ve takip ettiği kişi sayısı, gönderi sayısı, son dönemdeki takipçi artışı, gönderinin zamanı, içerik türü gibi değişkenler dikkate alınmıştır.

Etkileşim: Beğeni sayıları ile gönderilerin altına açıklama yazılıp yazılmaması, yorum sayıları olarak belirlenmiştir. Bu bölümde, hashtag \# kullanımı ve sayıları da dikkate alınmıştır. 
Verilerin analizinde Spss 26 istatistik program kullanılmıştır. Veriler frekans analizi ile yüzde hesabından yararlanılmıştır.

\section{Bulgular}

Bu bölümde yapılan içerik analizi sonucunda elde edilen bulgular "gazetecinin Instagram kimliği”, "içerik", "etkileşim” başlıklarıyla verilmiştir.

\section{Gazetecinin Instagram Kimliğinin Iç̧erik Analizine Yönelik Bulgular}

Araştırma kapsamında, incelemeye alınan gazetecilerin isimleri, Instagram profil isimleri, profilin açıklama kısmında yer alan bilgiler, açıklamadaki diğer sosyal medya hesap bağlantıları ve internet sayfaları ve iletişim bilgileri Tablo 1'de verilmiştir.

Tablo 1. Instagram Hesaplarna İlişkin Temel Bilgiler

\begin{tabular}{lllll}
\hline Gazeteci adı & Hesap adı & $\begin{array}{l}\text { Profilin Açılama Kısmında } \\
\text { Yer Alan Bilgiler }\end{array}$ & $\begin{array}{l}\text { Açıklama Kıs- } \\
\text { mında Diğer } \\
\text { Sosyal Medya } \\
\text { Hesap Linkleri }\end{array}$ & $\begin{array}{l}\text { Açılama Kısmında } \\
\text { İnternet Sayfası } \\
\text { İletişim } \\
\text { Bilgileri }\end{array}$ \\
\hline $\begin{array}{l}\text { İsmail } \\
\text { Küçükkaya }\end{array}$ & ismailkucukkaya & yok & yok & yok \\
\hline Ayşe Arman & armanayse & yok & yok & www.armanayse.com \\
\hline Pelin Kaya & modavesosyete & $\begin{array}{l}\text { Fashion\&LifeStyle Journalist/ } \\
\text { Columnist }\end{array}$ & Youtube & $\begin{array}{l}\text { @sabah.gunaydin } \\
\text { modavesosyete@gmail.com }\end{array}$ \\
\hline
\end{tabular}

Tablo 1 incelendiğinde, İsmail Küçükkaya profilinde herhangi bir açıklamaya yer vermemiştir. Ayşe Arman'ın profilinin açıklama kısmında, internet sitesine bağlantı verdiği görülmektedir. Pelin Kaya ise, profilinde Fashion\&LifeStyle Journalist/Columnist vurgusu yapmış, Youtube kanall, yazılarını yazdığı gazetenin Instagram profili bağlantısını ve mail adresini vermiştir.

\section{Gazetecinin Instagram İçeriğinin İçerik Analizine Yönelik Bulgular}

Çalışmanın bu bölümünde, gazetecilerin toplam takipçi ve takip edilen sayılarına, toplam gönderi sayıları ile resim ve videoların gönderi sayılarına, ortalama etkileşim oranına, son dönemdeki takipçi artışlarına, paylaşım zamanına ve içerik konularına yer verilmiştir. 
Tablo 2. Instagram Hesaplarına İlişkin Genel Bilgiler

\begin{tabular}{lcccccccc}
\hline Gazeteci adı & $\begin{array}{c}\text { Takipçi } \\
\text { Sayısı }\end{array}$ & $\begin{array}{c}\text { Takipçi } \\
\text { Sayısı } \%\end{array}$ & $\begin{array}{c}\text { Takip } \\
\text { Edilen } \\
\text { Sayısı }\end{array}$ & $\begin{array}{c}\text { Takip } \\
\text { Edilen } \\
\text { Sayıs1 } \\
\%\end{array}$ & $\begin{array}{c}\text { Toplam } \\
\text { Gönderi } \\
\text { Sayıı }\end{array}$ & $\begin{array}{c}\text { Toplam } \\
\text { Gönderi } \\
\text { Sayısı } \%\end{array}$ & $\begin{array}{c}\text { Ortalama } \\
\text { Etkileşim } \\
\%\end{array}$ & $\begin{array}{c}\text { Son Dönemde } \\
\text { Takipçi Artıs }\end{array}$ \\
\hline Ayşe Arman & 1685556 & 37,4 & 1686 & 38,5 & 8521 & 37,6 & 1,6 & 8182 \\
\hline İsmail Küçükkaya & 1443966 & 32,0 & 211 & 4,8 & 6513 & 28,7 & 2,7 & $-2,205$ \\
\hline Pelin Kaya & 1379764 & 30,6 & 2485 & 56,7 & 7645 & 33,7 & 0,7 & 583 \\
\hline Toplam & 4509286 & 100,0 & 4382 & 100,0 & 22679 & 100,0 & & \\
\hline
\end{tabular}

Tablo 2'ye göre, Ayşe Arman'ın hesabı hesaplar içerisinde en çok takip edilen hesap olup $(\% 37,4)$ Pelin Kaya'nın takipçisi diğerlerine oranla daha azdır $(\% 30,6)$. Kişilerin takip ettiği kişi sayıları incelendiğinde Pelin Kaya'nın daha çok hesap takip ettiği $(\% 56,7)$ İsmail Küçükkaya ise oldukça az hesab1 takip ettiği anlaşılmaktadır $(\% 4,8)$.

Gönderi sayıları incelendiğinde, en çok paylaşım yapan Ayşe Arman iken (\%37,6), İsmail Küçükkaya daha az paylaşım yapmaktadır (\%28,7). Etkileşim oranında ise, İsmail Küçükkaya'nın hesabı en yüksek iken (\%2,7) Pelin Kaya'nın hesabı en düşüktür (\%0,7). Ayrıca, son 1 haftadaki takipçi değişimi incelendiğinde, İsmail Küçükkaya'da düşüş görülmekte iken $(-2,205)$ Ayşe Arman'da daha fazla artış görülmektedir (8182).

Tablo 3. Instagram Hesaplarına İlişkin Gönderi İstatistikleri

\begin{tabular}{|c|c|c|c|c|c|c|c|c|c|}
\hline Gazeteci adı & 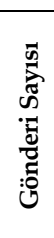 & 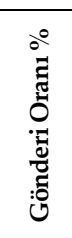 & 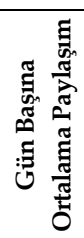 & 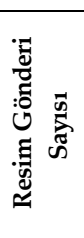 & 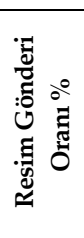 & 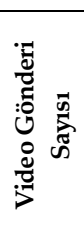 & 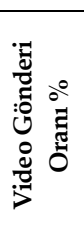 & 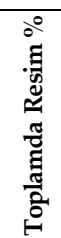 & 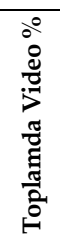 \\
\hline Ayşe Arman & 80 & 49,7 & 2,7 & 70 & 51,9 & 10 & 38,5 & 87,5 & 12,5 \\
\hline İsmail Küçükkaya & 56 & 34,8 & 1,9 & 48 & 35,6 & 8 & 30,8 & 85,7 & 14,3 \\
\hline Pelin Kaya & 25 & 15,5 & 0,8 & 17 & 12,6 & 8 & 18,2 & 68,0 & 32,0 \\
\hline Toplam & 161 & 100,0 & & 135 & 100,0 & 26 & 100,0 & & \\
\hline
\end{tabular}

Tablo 3 incelendiğinde, son 1 ayda en çok paylaşım Ayşe Arman tarafından yapıldığı $(\% 49,7)$ görülmekte olup, Pelin Kaya en az paylaşım yapandır $(\% 15,5)$. Paylaşım olarak resim içerikleri paylaşanlarda en yüksek oran Ayşe Arman'da iken $(\% 51,9)$ Pelin Kaya' da en düşüktür $(\% 12,6)$. Paylaşım olarak video içerikleri paylaşanlarda en yüksek oran Ayşe Arman'dadır $(\% 38,5)$. 
Tablo 4. Instagram Hesaplarına İlişkin Paylaşım Zamanı Bilgileri

\begin{tabular}{lcccc}
\hline Gazeteci adı & $\begin{array}{c}\text { Haftaiçi } \\
\text { Gönderi Sayısı }\end{array}$ & $\begin{array}{c}\text { Haftaiçi } \\
\text { Gönderi \% }\end{array}$ & $\begin{array}{c}\text { Haftasonu } \\
\text { Gönderi Sayısı }\end{array}$ & $\begin{array}{c}\text { Haftasonu } \\
\text { Gönderi \% }\end{array}$ \\
\hline Ayşe Arman & 61 & 47,3 & 19 & 59,4 \\
\hline İsmail Küçükkaya & 49 & 38,0 & 7 & 21,9 \\
\hline Pelin Kaya & 19 & 14,7 & 6 & 18,7 \\
\hline Toplam & 129 & 100,0 & 32 & 100,0 \\
\hline
\end{tabular}

Tablo 4 incelendiğinde, hafta içi gönderi sayısı Ayşe Arman hesabında en çok iken (\%47,3), Pelin Kaya'da en düşüktür $(\% 14,7)$. Hafta sonu gönderi sayılarında yine Ayşe Arman'ın en yüksek orana (\%59,4), Pelin Kaya'nın ise en düşük orana sahip olduğu görülmektedir $(\% 18,7)$.

Paylaşım içerik bilgileri incelendiğinde, kişisel $(\% 60,3)$ ve reklam $(\% 58,3)$ içeriklerinde Ayşe Arman'ın hesabından en çok paylaşım yapıldığı görülmektedir. Moda, sosyete içerikleri incelendiğinde, Pelin Kaya'nın hesabından en çok paylaşım yapılmıştır. Siyaset $(\% 58,8)$ ve diğer $(\% 47,6)$ içeriklerde ise, İsmail Küçükkaya'nın hesabından yüksek oranda paylaşım yapıldığı görülmektedir.

Tablo 5. Instagram Hesaplarına İlişkin Paylaşım İçerik Bilgileri

\begin{tabular}{|c|c|c|c|c|c|c|c|c|c|c|}
\hline Gazeteci adı & 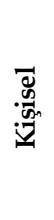 & 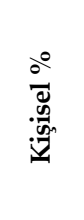 & 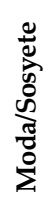 & 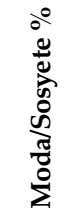 & 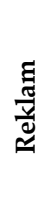 & 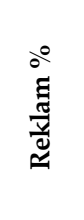 & 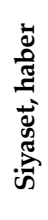 & 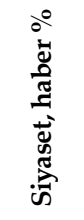 & 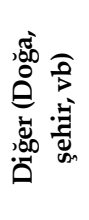 & 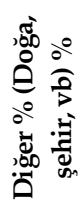 \\
\hline Ayşe Arman & 47 & 60,3 & 0 & 0 & 10 & 58,3 & 14 & 41,2 & 9 & 42,9 \\
\hline İsmail Küçükkaya & 26 & 33,3 & 0 & 0,0 & 0 & 0,0 & 20 & 58,8 & 10 & 47,6 \\
\hline Pelin Kaya & 5 & 6,4 & 15 & 100,0 & 7 & 41,7 & 0 & 0,0 & 2 & 9,5 \\
\hline Toplam & 78 & 100,0 & 15 & 100,0 & 17 & 100,0 & 34 & 100,0 & 21 & 100,0 \\
\hline
\end{tabular}

Gazetecilerin ilgi alanları doğrultusunda yaptıkları habercilik dikkate alındığında, genelde o yönde paylaşım yaptıkları görülse de doğa, şehir gibi iş alanları dışındaki diğer türdeki paylaşımların da İsmail Küçükkaya ile Ayşe Arman tarafından yapıldığı ve hesaplarını kişisel olarak da kullandıkları belirlenmiştir. 


\section{Gazetecinin Instagram Etkileşiminin İ̧erik Analizine Yönelik Bulgular}

Bu bölümde, gazetecilerin Instagram hesaplarına ilişkin beğeni ve yorum sayıları, paylaşılan içerik türlerine göre beğeni ve yorum sayıları ve hashtag kullanımları incelenmiştir.

Tablo 6'ya göre, İsmail Küçükkaya'nın resim içerikli paylaşımlarına beğeni oranı en yüksek iken (\%48,4) Pelin Kaya'da en düşüktür $(\% 7,1)$. Diğer yandan, Pelin Kaya'nın video içerikli paylaşımlarına beğeni oranı en yüksek iken $(\% 53,2)$ İsmail Küçükkaya' da en düşüktür $(\% 13,9)$. Toplam beğeni sayısı üzerinden değerlendirildiğinde en çok beğeni Ayşe Arman'ın hesabında (\%38), en düşük beğeni oranı ise İsmail Küu̧ükkaya'nın hesabında görülmektedir (\%29). Ayşe Armanın son bir aydaki 80 paylaşımı incelendiğinde, 70'inin resim, 10'unun video olduğu ve 47'sinin kişisel olduğu dikkate alındığında, kişisel paylaşımlarının yüksek oranda beğenildiği anlaşılmaktadır.

Tablo 6.Instagram Hesaplarna İlişkin Beğeni İstatistikleri

\begin{tabular}{|c|c|c|c|c|c|c|c|c|c|}
\hline Gazeteci adı & 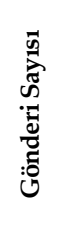 & 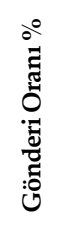 & 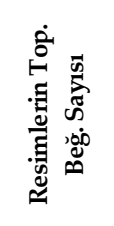 & 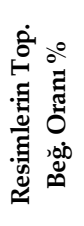 & 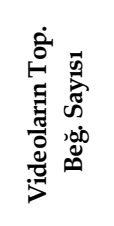 & 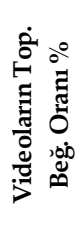 & 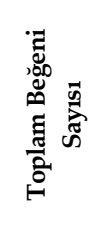 & 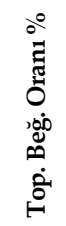 & 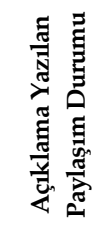 \\
\hline Ayşe Arman & 80 & 49,7 & 1717417 & 44,5 & 1637963 & 32,9 & 3355380 & 38,0 & Tamamı \\
\hline $\begin{array}{l}\text { İsmail } \\
\text { Küçükkkaya }\end{array}$ & 56 & 34,8 & 1867494 & 48,4 & 692093 & 13,9 & 2559587 & 29,0 & $\begin{array}{c}\text { Nere- } \\
\text { deyse } \\
\text { tamamı }\end{array}$ \\
\hline Pelin Kaya & 25 & 15,5 & 273084 & 7,1 & 2645032 & 53,2 & 2918116 & 33,0 & Tamamı \\
\hline Toplam & 161 & 100 & 3857995 & 100 & 4975088 & 100 & 8833083 & 100 & \\
\hline
\end{tabular}

İsmail Küçükkaya'nın son bir ayda 56 paylaşım yaptığı, 48'inin fotoğraf olduğu ve kişisel paylaşımları ile diğer (doğa, şehir, vb.) paylaşımlarının toplamı \%80'in üzerinde olduğu dikkate alındığında, siyaset ve haber paylaşımlarından ziyade diğer paylaşımlarının yüksek oranda beğeni aldığı ortaya çıkmaktadır.

Pelin Kaya'nın son bir ayda 25 paylaşım yaptığı, 17'sinin fotoğraf, 8 'inin video olduğu, genellikle moda ve reklam üzerine paylaşımlar yaptığı, fakat videolarının beğeni oranı $(\% 53,2)$ fotoğraflardan $(\% 7,1)$ yüksek olduğu tespit 
edilmiştir. Burada videoların izlenme sayılarının beğeni olarak değerlendirildiği de dikkate alınmalıdır.

Tablo 7. Instagram Hesaplarna İlişkin Yorum İstatistikleri

\begin{tabular}{|c|c|c|c|c|c|c|c|c|}
\hline Gazeteci adı & 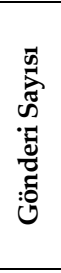 & 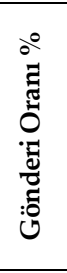 & 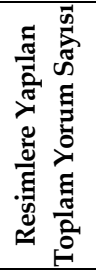 & 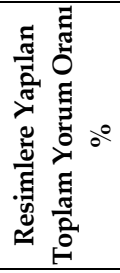 & 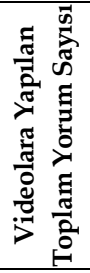 & 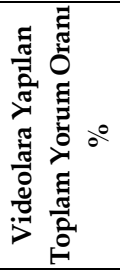 & 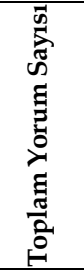 & 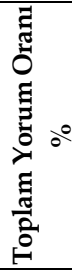 \\
\hline Ayşe Arman & 80 & 49,7 & 21400 & 36,0 & 3033 & 23,8 & 24433 & 33,8 \\
\hline İsmail Küçükkaya & 56 & 34,8 & 19552 & 32,9 & 6132 & 48,2 & 25684 & 35,6 \\
\hline Pelin Kaya & 25 & 15,5 & 18528 & 31,1 & 3560 & 28,0 & 22088 & 30,6 \\
\hline Toplam & 161 & 100 & 59480 & 100,0 & 12725 & 100 & 72205 & 100,0 \\
\hline
\end{tabular}

Tablo 7 incelendiğinde, Ayşe Arman'ın resim içerikli paylaşımlarına yorum oranı en yüksek iken (\%36) Pelin Kaya'da en düşük (\%31,1) olduğu görülmektedir. Videolara yapılan yorumlarda, İsmail Küçükkaya'nın video içerikli paylaşımlarına yorum oranının en yüksek olduğu $(\% 48,2)$, Ayşe Arman'ın ise en düşük olduğu $(\% 23,8)$ tespit edilmiştir.

Toplam yorum sayısı üzerinden değerlendirildiğinde, en çok yorum İsmail Küçükkaya paylaşımlarına yapılmış $(\% 35,6)$, en az yorum Pelin Kaya'nın paylaşımlarına yapılmıştır (\%30,6). Fakat her üç gazetecinin de toplam yorum sayılarını \%30’larda seyrettiği görülmektedir.

Tablo 8. Instagram Hesaplarına İlişkin Paylaşım İçeriklerine Göre Beğeni Bilgileri

\begin{tabular}{|c|c|c|c|c|c|c|c|c|c|c|}
\hline Gazeteci adı & 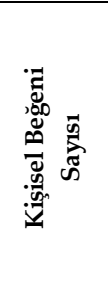 & 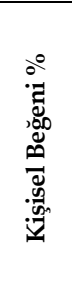 & 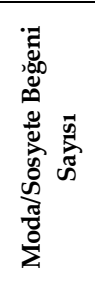 & 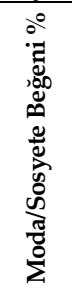 & 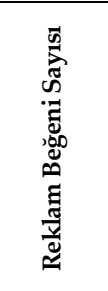 & 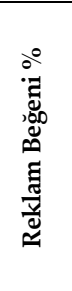 & 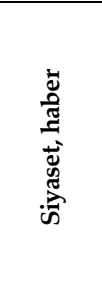 & 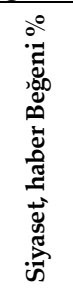 & 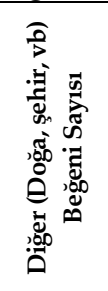 & 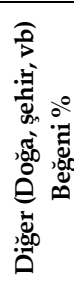 \\
\hline Ayşe Arman & 2118111 & 62,1 & 0 & 0,0 & 314486 & 20,0 & 454955 & 41,0 & 467828 & $\overline{21,0}$ \\
\hline $\begin{array}{l}\text { İsmail } \\
\text { Küçükkaya }\end{array}$ & 1259594 & 36,9 & 0 & 0,0 & 0 & 0,0 & 653746 & 59,0 & 646247 & 29,0 \\
\hline Pelin Kaya & 32200 & 0,9 & 514646 & 100,0 & 1255129 & 80,0 & 0 & 0,0 & 1116141 & 50,0 \\
\hline Toplam & 3409905 & 100,0 & 514646 & 100,0 & 1569615 & 100,0 & 1108701 & 100,0 & 2230216 & $\overline{100,0}$ \\
\hline
\end{tabular}


Tablo 8 incelendiğinde, kişisel $(\% 62,1)$ içeriklerde en çok beğeniyi Ayşe Arman'ın alırken siyaset, haber içeriklerinde en çok beğeniyi İsmail Küçükkaya almıştır (\%59). Moda, sosyete (\%100), reklam (\%80) ve diğer (\%50) içeriklerde de Pelin Kaya'nın hesabı en çok beğeni aldığı görülmektedir.

Gazetecilerin haber yaptıkları alanla ilgili paylaşımların beğeni oranları incelendiğinde, İsmail Küçükkaya ile Pelin Kayan'nın habercilik paylaşımlarının yüksek oranda beğenildiği görülse de Ayşe Arman'ın kişisel paylaşımlarının kaydadeğer oranda beğeni alması dikkat çekicidir $(\% 62,1)$.

Tablo 9. Instagram Hesaplarna İlişkin Paylaşım İçeriklerine Göre Yorum Bilgileri

\begin{tabular}{|c|c|c|c|c|c|c|c|c|c|c|}
\hline Gazeteci adı & 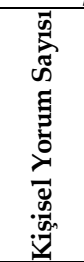 & 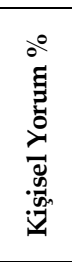 & 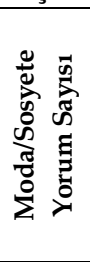 & 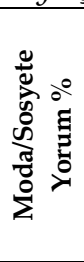 & 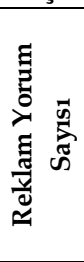 & 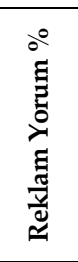 & 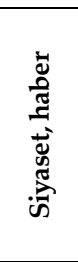 & 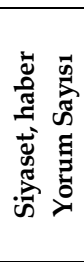 & 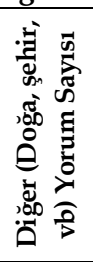 & 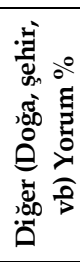 \\
\hline İsmail Küçükkaya & 15325 & 52,9 & 0 & 0,0 & 0 & 0,0 & 4129 & 38,0 & 6230 & 58,8 \\
\hline Ayşe Arman & 12898 & 44,5 & 0 & 0,0 & 1517 & 33,3 & 6725 & 62,0 & 3293 & 31,1 \\
\hline Pelin Kaya & 738 & 2,5 & 17240 & 100,0 & 3040 & 66,7 & 0 & 0,0 & 1070 & 10,1 \\
\hline Toplam & 28961 & 100,0 & 17240 & 100,0 & 4557 & 100,0 & 10854 & 100,0 & 10593 & 100,0 \\
\hline
\end{tabular}

Tablo 9 incelendiğinde, kişisel (\%52,9) ve diğer içeriklerinde (\%58,8) İsmail Küçükkaya'nın hesabının en çok yorum aldığı görülmektedir. Siyaset içeriklerinde ise en çok Ayşe Arman'ın paylaşımlarının yorum aldığı belirlenmiştir (\%62). Moda, sosyete (\%100) ile reklam (\%66,7) içeriklerinde ise en çok Pelin Kaya'nın paylaşımları yorum almış olup kişisel paylaşımlarına gelen yorumları oldukça düşük oranda olduğu bulunmuştur $(\% 2,5)$.

Tablo 10. Instagram Hesaplarında Paylaşım İçeriklerine Göre Hashtag (\#) Kullanımı

\begin{tabular}{|c|c|c|c|c|c|c|c|c|c|c|}
\hline Gazeteci adı & 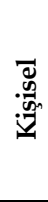 & $\begin{array}{l}\frac{0}{0} \\
\ddot{D} \\
\frac{0}{0}\end{array}$ & 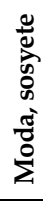 & 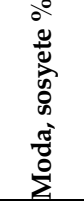 & 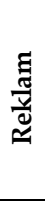 & 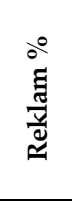 & 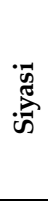 & 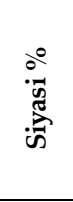 & 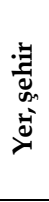 & 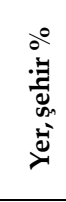 \\
\hline İsmail Küçükkaya & 2 & 6,9 & 0 & 0,0 & 0 & 0,0 & 1 & 12,5 & 0 & 0,0 \\
\hline Ayşe Arman & 23 & 79,3 & 0 & 0,0 & 1 & 20,0 & 7 & 87,5 & 1 & 50,0 \\
\hline Pelin Kaya & 4 & 13,8 & 13 & 100,0 & 4 & 80,0 & 0 & 0,0 & 1 & 50,0 \\
\hline Toplam & 29 & 100,0 & 13 & 100,0 & 5 & 100,0 & 8 & 100,0 & 2 & 100,0 \\
\hline
\end{tabular}


Tablo 10'da yer alan Instagram hesaplarında kullanılan hashtagler incelendiğinde, siyasi $(\% 87,5)$ ve kişisel $(\% 79,3)$ tagler en çok Ayşe Arman tarafından kullanılmıştır. Moda, sosyete $(\% 100,0)$ ile reklam $(\% 80)$ tagleri ise daha çok Pelin Kaya'nın paylaşımlarında kullanılmıştır. Yer, şehir tagleri'nin ise, Ayşe Arman ve Pelin Kaya tarafından eşit oranda kullanıldığı görülmektedir (\%50). İsmail Küçükkaya'nın siyasi tag'leri \%12,5, kişisel tag'leri ise \%6,9 oranında kullandığı belirlenmiştir.

\section{Tartışma ve Sonuç}

Zaman geçtikçe, gazetecilik endüstrisi, yalnızca tek bir teknolojik ilerleme faktöründen ötürü değil, aynı zamanda sosyal, ekonomik ve politik değişiklikler gibi diğer faktörlerle olan korelasyonu sebebiyle de çeşitli kademeli değişiklikler geçirmiştir (Wijaya, 2019). Bu değişimlerle birlikte, halkın ilgi ve beklentisine yönelik gazetecilikte kendi içinde yeni yollar keşfetmeye başlamıştır. Bu anlamda zamanın getirdiği her bir etkenle gazeteciliğin de sinerji içinde çalıştığını ve değişime uğradığını söylemek yanlış olmayacaktır.

Instagram gazeteciliği günümüz modern gazetecilik sektörünün en önemli platformlarından biri haline gelmiştir. Yayınlanan her türlü içeriğe hızlı bir şekilde erişim kolaylığı sağlıyor olması ve takipçilerle aktif bir etkileşim içinde bulunma imkânını temin ediyor olması, bu alanda ön plana çkmak isteyen ve sesini duyurmak isteyen her kesim insan için bir avantaj haline dönüşmüştür. Özellikle Instagram'ın kendini sürekli yenileyen bir platform ile yeni nesil kuşağa hitap ediyor olması da son yıllarda birçok gazetecinin TV programcilığındaki şöhretini büyütmesine olanak tanır hale gelmiştir. Modayla, sanatla, kişinin yaşam stili ve tarzıyla, gittiği mekânlarla, eş-dost çevresi ile ve elbette hitap ettiği kitleye arzuladıkları bilgi ve dedikoduyu sağlayabilme imkânlarıyla takipçi sayısını günden güne arttırması mümkündür.

Instagram'da aktif bir kullanım sergilemek, olayları ve gündemi her an takip edip paylaşımlarda bulunuyor olmak da kişinin hedef takipçi sayısına ulaşmasına olanak tanımaktadır. Kişinin profil kısmında yer alan bilgileri, kendisi hakkında ipucu verme olanağı sağlarken, açıklama kısmında vereceği sosyal medya hesap linkleri ise yoğunlaşmak istediği sosyal medya mecrasındaki takipçi kitlesine hızlı bir şekilde ulaşmasına da olanak tanımaktadır. Ayrıca var ise, internet sayfası ve iletişim bilgileri ile de hitap ettiği ku- 
şakların iletişim tercihlerine de önem vermiş olup, sesini duyurduğu kuşaklar ile iletişimini güçlendirebilmektedir. Bu bağlamda Ayşe Arman ve Pelin Kaya'nın profillerinde artı bir iletişim olanağı sağlıyor olması takipçilerinin gün ve gün arttırıyor olmasında önemli bir faktör olarak değerlendirilebilir. Ne kadar geniş bir kitle ile etkileşim sağlanırsa o kadar sağlam takipçi profili oluşturmak mümkün olacaktır.

Günümüzde gelinen noktada, takipçi sayısı arttıkça, kişinin popülaritesi de artmaktadır. Elde edilen popülarite ile beraber yeni neslin o profili yorumlama unsurlarından biri de takip ettiği kişi sayısıdır. Instagram' da halka hitap eden sanatçıların, gazetecilerin ve siyasetçilerin hesapları göz önünde bulundurulduğunda bu bakış açısını kabul ettikleri ve ne kadar çok takipçileri var ise o kadar az takip ettikleri kişilerin olduğu gözlemlenmektedir. Ancak değerlendirmede bulunulan üç gazeteci için aynı şeyleri söylemek mümkün olmayacaktır. Ayşe Armanı'n, İsmail Küçükkaya ve Pelin Kayaya göre daha çok takipçisinin olduğu göz önünde bulundurulduğunda, takip ettiği kişi sayısı yadırganamayacak düzeyde fazladır, ancak İsmail Küçükkaya'nın bu yeni nesil bakış açısına uygun bir şekilde az takibinin olduğunu söylemek doğru olacaktır. Bu etkenin takipçi sayısını ne ölçüde etkilediği tam olarak bilinemese de en azından bu konuyu ciddiye alan yadırganamayacak sayıdaki önemli profillerin varlığından söz etmek mümkündür.

Ayrıca, Instagram'daki aktif paylaşım sıklığı göz önünde bulundurulduğunda bu üç gazeteci içinde en aktif paylaşımda bulunan Ayşe Arman'ın en çok takipçiye sahip olmasına pek de şaşırılmamalıdır. Genel bir değerlendirme yapılır ise, Instagram'daki hafta içi ve hafta sonu paylaşımları değerlendirildiğinde her ikisinde de en aktif olan Ayşe Arman'ın en çok takipçiye sahip olduğunu gözlemlenmektedir. Aktif bir profile sahip olmanın Instagram için çok önemli bir husus olduğu zaten bilinmektedir. Bulunan sonuç da bu görüşü doğrulamıştır.

Paylaşımlarında kişisel hayatıyla ilgili yine bu üç gazeteciye oranla Ayşe Arman daha fazla paylaşımda bulunmaktadır. Kişisel hayatla ilgili bilgi edinilmesine olanak sağlanması takip edenlerin gezilecek görülecek yerler listesinde Ayşe Arman'ın listesini hayatlarına koymalarını etkilemiştir. Instagram'daki aktifliği dolayısı ile daha fazla reklam aldığı ön görülür ise, profilinde en çok reklam paylaşımında bulunan ismin de aynı kişi olması şaşırt- 
mamaktadır. Siyaset ve doğa, şehir hayatıyla ilgili paylaşımlarda İsmail Küçükkaya ile yakın bir profil sergilese de, bu alanda daha az paylaşımda bulunduğu gözlerden kaçmamaktadır.

Diğer yandan, gönderilerin altına yapılan yorumlar değerlendirildiğinde, yine en çok takipçi sayısına sahip Ayşe Arman olsa da İsmail Küçükkaya'nın video paylaşımlarına daha çok ilginin olduğunu söylemek yanlış olmayacaktır. Genel değerlendirme yapıldığında her üç isminde kendilerini ön plana koydukları alanlarda hitap ettikleri kitlelerle daha fazla iletişim halinde oldukları ve beğeni oranlarının da bu yönde artış gösterdiği analiz sonuçlarına yansımaktadır. Bununla birlikte, etkileşim ve paylaşımların azlığı yönünden İsmail Küçükkaya'nın hashtag paylaşımlarının her iki gazeteciye oranla epey az olduğu ve bu durumun takipçi artışını olumsuz etkilediği görülmektedir. Hashtag kullanan Pelin Kaya'nın İsmail Küçükkaya kadar aktif olmasa dahi takipçi kaybetmediğinin görülmesi bu durumu desteklemiştir.

Goffman (1959), birçok kişinin çevresine güvenilir bir imaj yaratabilme doğrultusunda, sözel ve sözel olmayan verileri kullanarak, şekillendirdikleri kimlikler ile imgelerinin seslerini duyurduklarını iddia etmektedir. Kişi veya kişilerin öz-sunumları (self-presentation) hedef amaçlı olma eğilimindedirler (Leary ve Kowalski, 1990), bu sebeptendir ki, çevrelerine kendi benliklerini nasıl yansıttıklarını göz önünde bulundurarak, hem onların arzularını hem de bireysel amaçlarını, kendi benlikleri ile dengede tutmanın bir arayışı içindedirler (Bortree, 2005).

Geleneksel olarak, öz sunumun yüz yüze etkileşimle belli bir seviyeye kadar kişinin kendini ifade etmesine olanak tanıdığı bilinmektedir. Örneğin, bir kişi kendini tanıtmak istediğinde bunu fiziksel olarak yapması mümkündür, ancak kişinin fiziksel görünümü yansıtmak istediği öz sunumuyla örtüşmeyebilmektedir ve karşı tarafta şüphe uyandırabilmektedir. Ancak internet çağının sunduğu online platformlar sayesinde, kişiler kendi öz sunumları hakkında daha fazla kontrol alanına sahip olmuştur. Hem fiziksel hem görsel hem de işitsel kapsamda yansıtmayı hedefledikleri öz sunumları için birçok imkân bu platformlar üzerinden sunulmaktadır. Bu nedenle, araştırmacılar; kişi/kişilerin geniş kapsamda öz sunumunu çevrimdışı çevrelerinde yapabilme imkânına sahip olmalarında dahi, yeni çevrimiçi dünyada öz sunumlarını diledikleri ölçüde ve daha kapsamlı bir şekilde yansıtabilme olanağına sahip olduklarını iddia etmektedirler (Caplan, 2005; Gibbs, Ellison ve Heino, 2006; Papacharissi, 2002). 
Gerçek şudur ki, özetle, bir kişi yüz yüze etkileşim yoluyla belirli bir ölçüde kendini sunabilme imkanına sahipken, çevrimiçi sitelerin sağladığı konfigürasyon süreçleri kişilere bu açıdan daha fazla özelleştirme sunmaktadır. $\mathrm{Bu}$ özelleştirmeler ile de kişiler hangi kendileri ile ilgili vermek istedikleri ipuçları ne ise onu yansıtmaktadırlar. Bu anlamda hitap etmek istedikleri kitleyi de belirleyebilme imkanına sahip olabilmektedirler. Bunu destek nitelikte bir yandan da sosyal medya'nın kullanıcılarına sunduğu öz sunum imkânları sürekli bir şekilde gelişmeye ve zenginleşmeye devam etmektedir (Rosenberg ve Egbert, 2011; Van Der Heide, D'Angelo ve Schumaker, 2012; Vitak, 2012).

Sonuç olarak, Instagram dinamiklerinin gazetecilerin takipçi artışındaki etkisinin ortaya koyulduğu bu araştırmada yeni nesil gazetecilik anlayışında Instagram kullanan gazetecilerin bir kanaat önderi olma pozisyonundaki rolleri toplumsal öneme sahiptir. Araştırmada içerik analizi yapılarak Türkiye'deki en çok takip edilen ve ilk beş arasında yer alan gazetecilerin Instagram hesaplarının incelenmesi, habercilik bağlamında gazetecilerin sosyal medya mecralarında yer edinmelerinde bir ipucu sağlayabilir. 


\title{
EXTENDED ABSTRACT
}

\section{Examining Journalists' Instagram Accounts in Turkey: A Content Analysis}

\author{
Aylin Tutgun Ünal - Ayşe Sena Kurt \\ Üsküdar University
}

Nowadays, as the news agency of social media, Instagram serves not only the visual sharing of young generations in the form of photo/video, but also the dissemination of informational content about both the business and private life of professionals. Working almost as a news agency, social media serves news organizations as the primary source with the photos and videos it shares. It is seen that almost all of the journalists benefit from social media channels.

Social media is used by large masses to produce and consume news worldwide. Therefore, it has been wondered how social media journalists use social networks. The high number of followers of journalists who are popular in our country shows this. Having a high number of followers imposes the responsibility of being an opinion leader. What opinion leaders say and how they say is important in today's widespread culture, which we call participatory culture.

Social media is the most common online example of participatory culture, and the same mechanism as in real life also works in social networks. In the internal control mechanism of social media, auditors are a kind of online users and can share opinions, likes or repost (retweet, repost, repin, etc.). According to this knowledge, considering that popular journalists have the power to influence society, the balance of their sharings about journalism and personal usage can provide clues as to why they are being followed.

In this study, three journalists Instagram account which is the top five with a high number of followers in Turkey are analyzed according to content analysis. First of all, journalists are listed in terms of the number of Instagram followers and then, accounts of 5 journalists with more than 1,000,000 followers and managed by a single person were taken into account. Afterward, the sample of Instagram accounts of 3 well-known names was formed, consider- 
ing that they are from different interests. The accounts that have been sampled and analyzed are İsmail Küçükkaya, Pelin Kaya, Ayşe Arman. When the areas of interest of journalists are examined, it's seen that Pelin Kaya is interested in fashion and high society, Ayşe Arman is interested in interview news, and İsmail Küçükkaya is interested in news reporting.

Journalists' Instagram pages are analyzed under three headings: "Journalist's Instagram Identity", "Content" and "Interaction". Some of the findings obtained as a result of the research are as follows: (a) The use of hashtags affects the increase in the number of followers, (b) İsmail Küçükkaya makes $80 \%$ personal shares from his account rather than his business area, (c) Ayşe Arman who shared the most posts on Instagram compared with the other two journalists shared 80 posts in a month. The second one is İsmail Küçükkaya with 56 posts and Pelin Kaya with 25 posts in the third place, d) Personal posts are the most liked. When Ayşe Arman's 80 posts in the last month were examined, considering that 70 of them were pictures, 10 of them were videos, and 47 of them were personal, it was understood that why her personal posts were highly appreciated. It has been taken into consideration that İsmail Küçükkaya has shared 56 shares in the last month, 48 of them are photographs and the total of his personal and other (nature, city, etc.) shares are over $80 \%$. It has been revealed that his other posts rather than politics and news posts are highly appreciated.

It has been determined that Pelin Kaya has made 25 posts in the last month, 17 of them are photographs, 8 of them are videos, and she generally posts on fashion and advertising. However, it was determined that her videos had a higher appreciation rate (53.2\%) than photographs (7.1\%)

As a result of the research, it was understood that the hashtags used by journalists together with their personal posts are effective in the number of followers. It is understood from the number of views that video content is more effective because it contains more interaction than photographs, as in the example of Pelin Kaya. Maximum usage of visual features is effective in increasing followers.

In conclusion, it is clear that Instagram journalism has become one of the most important platforms of today's modern journalism industry. In this study, which revealed the effect of Instagram dynamics on the increase of journalists' followers, the role of journalists using Instagram in the position of opinion leaders in the new generation journalism approach was found to be 
important. By making content analysis in the research, examining the Instagram accounts of journalists who are among the most followed and top five in Turkey can provide a clue to the place of journalists in social media in the context of journalism.

\section{Kaynakça / References}

Asmafiliz, E., ve Şalvarcı Türeli, N. (2018). Y kuş̧ağı bireylerin sosyal medya kullanım sıklığı üzerine amprik bir araştırma, 5th International Conference on Social Sciences and Education Research Bildiriler Kitabr içinde (s.294-312).

Bortree, D. S. (2005). Presentation of self on the Web: An ethnographic study of teenage girls' Web logs. Education, Communication, \& Information, 5, 25-39.

Byrd, R. D., ve Denney, P. (2018). Using their own voice: Learning to tell stories with Instagram. Teaching Journalism \& Mass Communication. 8(2), 47-55. http://www.aejmc.us/spig/journal adresinden erişilmiştir.

Caplan, S. E. (2005). A social skill account of problematic internet use. Journal of Communication, 55, 721-736.

Dyke M. V., Haynes C ve Ferguson M (2007). Bridging the divide: A public relations perspective on intergenerational communication. Public Relations Quarterly, $52,4,19-23$.

Gibbs, J. L., Ellison, N. B., Heino, R. D. (2006). Self-presentation in online personals: The role of anticipated future interaction, self-disclos.

Golbeck, J. (2015). Instagram: Introduction to social media investigation, 159-170. doi: https://doi.org/10.1016/B978-0-12-801656-5.00015-9.

Goffman, E. (1959). The presentation of self in everyday life. New York, NY: Double Day.

Handley, L. (2019). Facebook is at the point of no return: These 17-year-olds are very clear about what they love and hate about social media. CNBC. https://www.cnbc.com/2019/07/31/facebook-instagram-snapchat-what-teenagers-think-of-social-media.html adresinden erişilmiştir.

Harcup, T., ve O'Neill, D. (2017). What is news? News values revisited (again). Journalism Studies, 18(12), 1470-88.

Jenkins, H. (2006). Convergence culture: Where old and new media collide. New York, London: New York University Press.

İrvan, S. (2014). İnternet gazeteciliğinde firsatlar ve tehditler. Yeni Düzen. http://www.yeniduzen.com/internet-gazeteciliginde-firsatlar-ve-tehditler2981yy.htm adresinden erişilmiştir. 
Keskin, H. D., ve Çilingir, Z. (2010). Web sitelerinin globalizasyonu üzerine büyük global Amerikan markalarına yönelik bir içerik analizi uygulaması. Eskişehir Osmangazi Üniversitesi Ï̈BF Dergisi, 5(2), 51-66.

Kinsky, E.S., ve Bruce, K. (2016). It throws you into the ring: Learning from live-tweeting. Teaching Journalism and Mass Communication, 6(1), 36-52.

Kuyucu, M. (2017). Y kuşağı ve teknoloji: Y kuşağının iletişim teknolojilerini kullanım alıskanlıkları. Gümüşhane Üniversitesi Illetişim Fakültesi Elektronik Dergisi, 5(2), 845-872.

Lamble, S. (2011). News as it happens: An introduction to journalism. Melbourne: Oxford University Press.

Lasica, J.D. (2003). Blogs and journalism need each other. NiemanReports, 57(3), 70-4.

Leary, M. R., Kowalski, R. M. (1990). Impression management: A literature review and two component model. Psychological Bulletin, 107, 34-47.

Marwick, A.E. (2018). Why do people share fake news? A sociotechnical model of media effects. Georgetown Law Technical Review, 2, 474-512.

Özdemir, Ş. (2017). Kuşaklar teorisine göre Türkiye'deki gençlerin medya kullanm alı̧kanlklan ve İstanbul örneği. Yayımlanmamış Yüksek Lisans Tezi, Marmara Üniversitesi, İstanbul.

Papacharissi, Z. (2002). The presentation of self in virtual life: Characteristics of personal home pages. Journalism \& Mass Communication Quarterly, 79, 643-660.

Park, S., Fisher, C., Fuller, G., ve Lee, J.Y. (2018). Digital news report. Australia 2018. News and Media Research Centre, University of Canberra.

Rosenberg, J., ve Egbert, N. (2011). Online impression management: Personality traits and concerns for secondary goals as predictors of self-presentation tactics on Facebook. Journal of Computer-Mediated Communication, 17, 1-18.

Sablich J. (2019). Three ways journalists should be using Instagram. https:/www.nyguild.org/front-page-details/three-ways-journalists-shouldbe-using-instagram adresinden erişilmiştir.

Sağır, A., ve Eraslan, H. (2019). Akıllı telefonların gençlerin gündelik hayatlarına etkisi: Türkiye'de üniversite gençliği örneği. OPUS-Uluslararası Toplum Araştırmalan Dergisi, 10(17), 48-78. http://dx.doi.org/10.26466/opus.515339

Singer, J.B., Hermida, A., Domingo, D., Heinonen, A., Paulussen, S., Quandt, T., Reich, Z., ve Vujnovic, M. (2011). Participatory journalism: Guarding open gates at online newspapers. Wiley-Blackwell, West Sussex.

Süer, S., Sezgin, K., ve Oral, B. (2017). Z kuşağındaki öğrencilerin internete ilişkin algilarının belirlenmesi: Bir metafor çalısması, Elektronik Eğitim Bilimleri Dergisi, 6(12), 190-203. 
Tutgun-Ünal, A. (2020a). Sosyal medya gazeteciliği. G.E. Atalay, (Ed.) Yeni medya ve alternatif gazetecilik: Yeni olanaklar, sorunlar ve tartısmalar, içinde (s.43-90).İstanbul: Hiperyayın,

Tutgun-Ünal, A. (2020b). Yeni medya ile yeni gazetecilik anlayışı: Haber ajanslarının sosyal medya gazeteciliği açısından incelenmesi. Erciyes İletişim Dergisi, 7(2), 1011-1031. https://doi.org/10.17680/erciyesiletisim.647078

Tutgun-Ünal, A., ve Deniz, L. (2020). Sosyal medya kuşaklarının sosyal medya kullanım seviyeleri ve tercihleri. OPUS-Uluslararası Toplum Araştırmalan Dergisi, 15(22), 125-144.

Van Der Heide, B., D'Angelo, J. D., ve Schumaker, E. M. (2012). The effects of verbal versus photographic self-presentation on impression formation in Facebook. Journal of Communication, 62, 98-116.

Vitak, J. (2012). The impact of context collapse and privacy on social network site disclosures.Journal of Broadcasting \& Electronic Media, 56, 451-470

Wijaya, C. (2019). Effective use of Instagram as a social media tool for the Conversation Media Group. The Conversation Media Group: The University of Melbourne, p.1.

Wilding, D., Fray, P., Molitorisz, S., ve McKewon, E. (2018). The impact of digital platforms on news and journalistic content, Australia: University of Technology Sydney.

Wilnat, L., ve Weaver, D. (2014). The American journalist in the digital age: Key findings. Bloomington: School of Journalism, Indiana University. http://www.news.indiana.edu/releases/iu/2014/05/2013-american-journalistkey-findings.pdf adresinden erişilmiştir.

Yeniçıkt, N. A. (2016). Halkla ilişkiler aracı olarak Instagram: Sosyal medya kullanan 50 şirket üzerine bir araştırma. Selçuk Üniversitesi İetişim Fakültesi Akademik Dergisi, 9(2), 92-115. doi: 10.18094/si.84410.

\section{Kaynakça Bilgisi / Citation Information}

Tutgun-Ünal, A. ve Kurt, A.S. (2021). Türkiye' deki gazetecilerin instagram hesaplarının içerik analizi. OPUS-Uluslararası Toplum Araştırmaları Dergisi, 17(33), 252-277. DOI: 10.26466/opus.830479 